\title{
Investigating Regional Disparities of Preschool Education Development with Cluster Analysis in Mainland China
}

\author{
Xiumin Hong \\ Beijing Normal University
}

\author{
Li Luo \\ University of Florida
}

China

\author{
Fangfang Cui \\ China Rehabilitation Research \\ Center for Deaf Children
}

\begin{abstract}
The unbalanced development of preschool education in different regions severely hinders the process of universalizing preschool education in Mainland China. Using the method of cluster analysis, this paper examined the extent to which the development of preschool education varied in different regions, on the basis of the gross preschool enrollment rate, student-to-teacher ratio, percentage of preschool teachers with a college diploma or above, and per-child preschool education spending index in the year of 2011. This paper suggested 31 provinces in Mainland China be divided into three developmental tiers according to their developmental status of preschool education, and explored each tier's characteristics in their development of preschool education. One significant finding was that the regional disparities in the development of preschool education correlated with the regional economic disparities in Mainland China.
\end{abstract}

Key words: preschool education, regional disparities, cluster analysis

\section{Introduction}

Given the importance of preschool education realized by the Chinese

Correspondence concerning this report should be addressed to Xiumin Hong, Associate Professor, Department of Early Childhood Education at Beijing Normal University, No. 19, Xin Jie Kou Wai Street, Beijing Normal University, Beijing, PRC, 100875. Electronic mail may be sent to xiuminhong@bnu.edu.cn

* This article is supported by MOE (Ministry of Education in China) Project of Humanities and Social Sciences (Project No.11YJC880028) \& "the Fundamental Research Funds for the Central Universities" people and the increasing investment put into preschool education by the Chinese government recently, it is not surprising that both the number of preschools and the number of enrolled children have drastically increased (Preschool usually refers to full-day programs serving 3- to 6-year-old children with focus on education and care in Mainland China). Since it is the first stage and important foundation of the national education system, the equity of preschool education is the cornerstone of the education equity and harmonious society. However, in the contemporary China, preschool education 
has been as ever the soft spot of the current education system and the strikingly lagging preschool education in rural and undeveloped areas has been egregious (Peng, 2007). During the rapid development of preschool education in the last three decades, one significant problem is the unbalanced development among regions, which not only appears in quantity but also shows up in quality and efficiency (Cai \& Feng, 2004; World Bank, 2011). Taking Shaanxi province as example, Jia and Liu (2011) analyzed local government's effort in ensuring regional balance of financial investment in preschool education. Wei and Song (2011) further investigated the unbalanced development of preschool education in eastern, central and western China from the perspective of education equity. They found that glaring developmental gaps among three different regions is growing. Resulting from economic, social, cultural, historical and regional factors, this problem, if not be treated seriously, will definitely hamper the quality of preschool education and our progress toward equal access to education. As is well-known, high quality education is one necessary condition of economic development. As a result, a premise of eliminating disparities of regional economic development is to narrow the gap of educational development in different regions (Wang, Du, \& Liu, 1998). In addition, the strategic goal of preschool education stipulated in Outline of China's National Plan for Medium and Long-term Education Reform and Development (2010-2020) is to universalize preschool education. “Up to the year 2020, all children in China will have full access to one year of preschool education; most children in China should have full access to two years of preschool education, and three years of preschool education should be accessible for the children in developed areas." (Communist Party of China Central Committee \& State Council, 2010, Chapter 3[Article 5]). The Outline also highlights that the gross enrollment rate of three-year preschool education should be 70 percent by the year of 2020. This imbalance of regional educational development impedes the process of universalizing preschool education in Mainland China. Therefore, the unbalanced regional development of preschool education requires analysis, study and solution. The purpose of this study was to examine the current situation of unbalanced regional development of preschool education in Mainland China.

\section{Method}

\section{Cluster Analysis}

Cluster analysis is a multivariate technique used for organizing observed data into meaningful taxonomies, groups, or clusters on the basis of their similarity. The goal of cluster analysis is that the objects within a group be similar to one another and different from the objects in other groups. "The greater the similarity (or homogeneity) 
within a group and the greater the difference between groups, the better or more distinct the clustering" (Tan, Steinbach, \& Kumar, 2006, p. 490).

\section{Selection of Variables}

The key to measuring educational development is to select the right indicators, which should not only reflect the comprehensive education development precisely, but can also be checked easily and comparatively. At present, the number of indicators for preschool education in Chinese official statistics is limited. Some important indicators are absent compared to that of compulsory education. This study combined statistical indicators of compulsory education in Mainland China and indicators of preschool education in developed countries, in order to examine the currently unbalanced regional preschool education status in Mainland China.

The statistical indicators of preschool education adopted by members of the Organization for Economic Co-operation and Development (OECD) included per-child preschool education spending index, the proportion of per-child preschool education spending index in per-capita GDP, the proportion of preschool education spending in GDP, teacher-child ratio, the proportion of preschool education spending in total education spending, and the ratio of the number of children enrolled in preschool to the total student enrollment (OECD, 2005). When evaluating the popularization and progress of compulsory education in Mainland China, the Intelligence Development Institute of Shanghai Educational Science College used six indicators: the enrollment rate for primary school-aged children, five-year retention rate of primary school, promotion rate of primary school graduates, gross enrollment rate of new junior students, gross enrollment rate of junior students, and gross enrollment rate of junior school graduates (Xu \& Ma, 1997). Additionally, the Research Team of China Education and Human Resource Problems (2003) highlighted four core indicators-five-year retention rate of primary school, three-year retention rate of junior school, student-to-teacher ratio at all levels of education, and the ratio of qualified full-time teachers at all levels of education-- in measuring the quality and efficiency of educational development. When assessing educational development level, we should consider not only the indicators for scale and numbers, but also that for quality. It is not appropriate to evaluate educational development only by the absolute magnitude indicators; the better choice is to select the ratio indicators such as enrollment rate. The indicator "perstudent education spending" could be considered as an indirect measurement of the quality of educational development (Du, 2000). On the basis of previous research and characteristics of preschool education, this study used four indicators including gross preschool enrollment rate, student-to-teacher ratio, percentage of preschool teachers with a college diploma or above, and per-child preschool 
education spending index, for the purpose of investigating regional disparities of preschool education development in Mainland China..

\section{Data}

In this study, the number of enrolled preschoolers, the number of full-time teachers and staff, and the educational background/level of full-time teachers were derived from China Educational Finance Statistical Yearbook of 2011.

According to the outstanding Chinese research book Stride from a Country of Tremendous Population to a Country of Profound Human Resources, per-student education spending index can be calculated by the following formula (China Education and Human Resource Problems Research Team, 2003, p. 508). We also used this formula to calculate per-student preschool spending in the year of 2011. The 2011 data for expenditure on preschool education in 31 provinces were derived from China Educational Finance Statistical Yearbook of 2011, and the 2011 data of GDP per capital in 31 provinces were published in China Statistical Yearbook of 2012.

Educational Spending per Student Index $=$ $\frac{\text { Expenditure on All Levels of Education per Student in a Region }}{} \times 100$

In this study, gross preschool enrollment rate was the total preschool enrollment divided by number of children aged three through six. The number of children aged three through six in 2011 was the sum of the births in 2005, 2006, and 2007. The birth in each year was the annual average population multiplied by birth rate; the annual average population was half of the sum of population at the end of last year and that at the end of this year. The population at the end of the year in 2004, 2005, 2006 and 2007 and the birth rate were derived from China Statistical Yearbook of 2012.

These four indicators were converted into standard scores before cluster analysis. Since all of these indicators except student-to-teacher ratio had a positive correlation with the quality and efficiency of education, the student-to-teacher ratio was changed into teacher-student ratio in the process of cluster analysis. However, it still appeared as student-to-teacher ratio in this paper.

\section{Results}

\section{Three Tiers in the Development of Preschool Education}

Using the above four indicators as clustering variables, we conducted the cluster analysis to examine the current regional disparities of preschool education development in 31 provinces. As Table 1 showed, there existed three tiers in the development of preschool education in Mainland China. In other words, 31 provinces could be divided into three developmental levels according to their developmental status in preschool education. Tier 1 included Beijing and Shanghai, the twelve provinces in Tier 2 were Tianjin, Liaoning, Jiangsu, Zhejiang, Hainan, 
Fujian, Jiangxi, Shandong, Hubei, Gugandong, Chongqin, and Suchuan.

The remaining seventeen provinces fell into Tier 3; the last tier occupied 54.84 percent of 31 provinces in Mainland China, which showed that the development of preschool education in Mainland China is still at a low level. In addition, this distribution of provinces is closely related to their geographic location and economic development history (see Figure 1). Most provinces in Tier 1 and 2 are located in the eastern coastal regions, while provinces in Tier 3 are located in central and western China. Mainland China's economic development is seriously polarized.

In its discussion of economic development and regional inequality, the Seventh Five-Years Plan divided the country into three regions: eastern, central and western (Fan \& Sun, 2008). There are a few definitions of the three regions, which are changing over time. Academic and official definitions are also sometimes inconsistent. Generally, the eastern region is comprised of 11 provinces: Beijing, Tianjin, Hebei,
Liaoning, Shanghai, Jiangsu, Zhejiang, Fujian, Shandong, Guangdong, and Hainan. The central region is comprised of eight provinces including Heilongiiang, Jilin, Shanxi, Anhui, Jiangxi, Henan, Hubei, and Hunan. The western region includes the 12 provinces of Sichuan, Chongqion, Guizhou, Yunnan, Tibet, Shaanxi, Gansu, Qinghai, Ningxia, Xinjiang, Guangxi, and Inner Mongolia (Wang \& Shu, 2012). With superior natural resources, regional advantage and preferential policies, the economic growth rate in eastern China has been higher than that of central and western regions for a long time. In 2005, the Gross Region Production of the eastern region accounted for 59.52 percent of the country's total, while the proportion of the central regions was $23.49 \%$, and that of the western regions was $16.99 \%$ (Peng, 2007).

Compared to this classification, we can easily find that all provinces in the eastern region except Hebei belonging to Tier 1 and Tier 2 in this study; besides that, sixteen provinces among the seventeen belonging to Tier 3 are in

Table 1. Three Tiers in the Development of Preschool Education in Mainland China

\begin{tabular}{c|l|c}
\hline Tiers & \multicolumn{1}{|c}{ Provinces } & Number (\%) \\
\hline Tier 1 & Beijing, Shanghai & $2(6.45)$ \\
\hline Tier 2 & $\begin{array}{l}\text { Tianjin, Liaoning, Jiangsu, Zhejiang, Hainan, Fujian, Jiangxi, Shandong, } \\
\text { Hubei, Guangdong, Chongqin, and Sichuan }\end{array}$ & $12(38.71)$ \\
\hline Tier 3 & $\begin{array}{l}\text { Hebei, Shanxi, Inner Mongolia, Jilin, Heilongjiang, Anhui, Henan, Hunan, } \\
\text { Guangxi, Yunnan, Shaanxi, Gansu, Ningxia, Guizhou, Tibet, Qinghai, and } \\
\text { Xinjiang }\end{array}$ & $17(54.84)$ \\
\hline
\end{tabular}


the central and western regions, which occupied 80 percent of twenty provinces in the central and western regions. This fact showed that the development of preschool education in Mainland China also fits the economic rule that the eastern region is better off than the central and western regions.

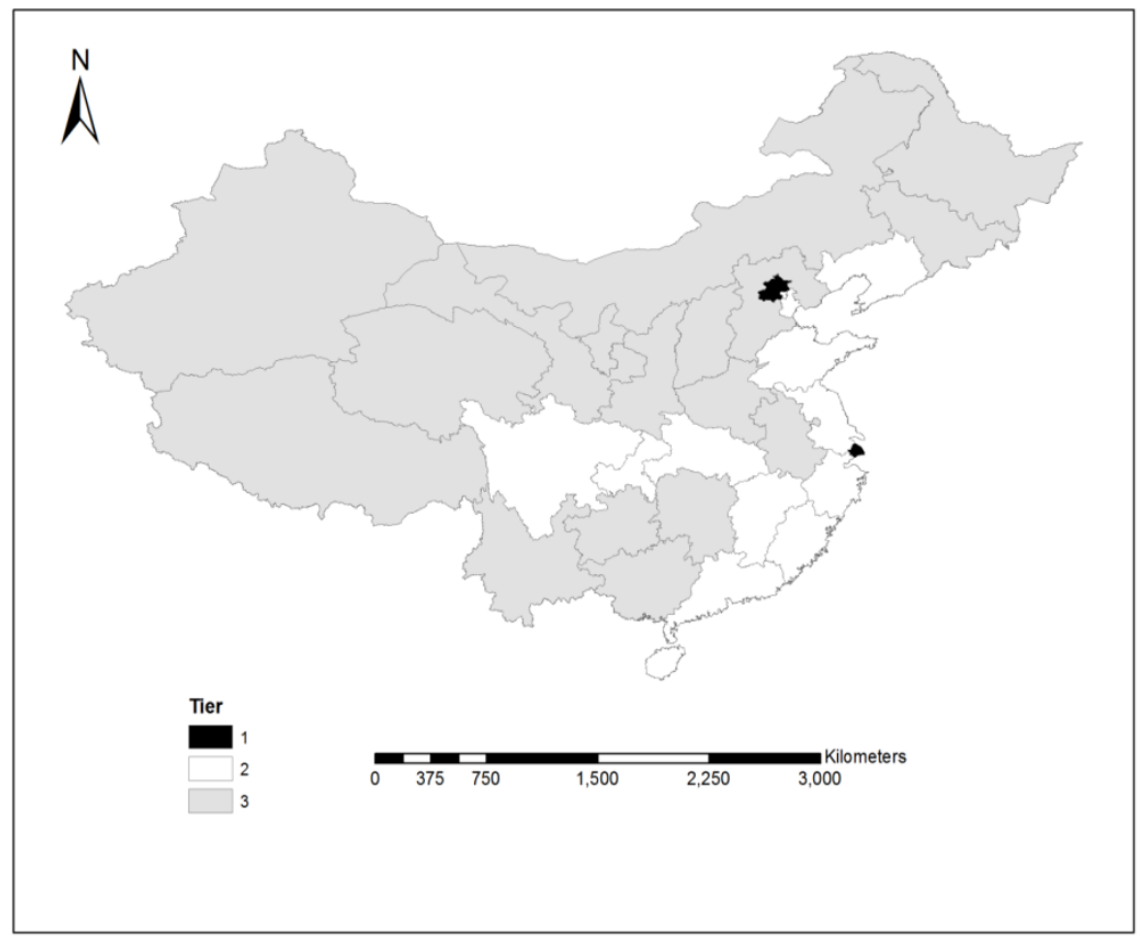

Figure 1. Geographic distribution of three tiers

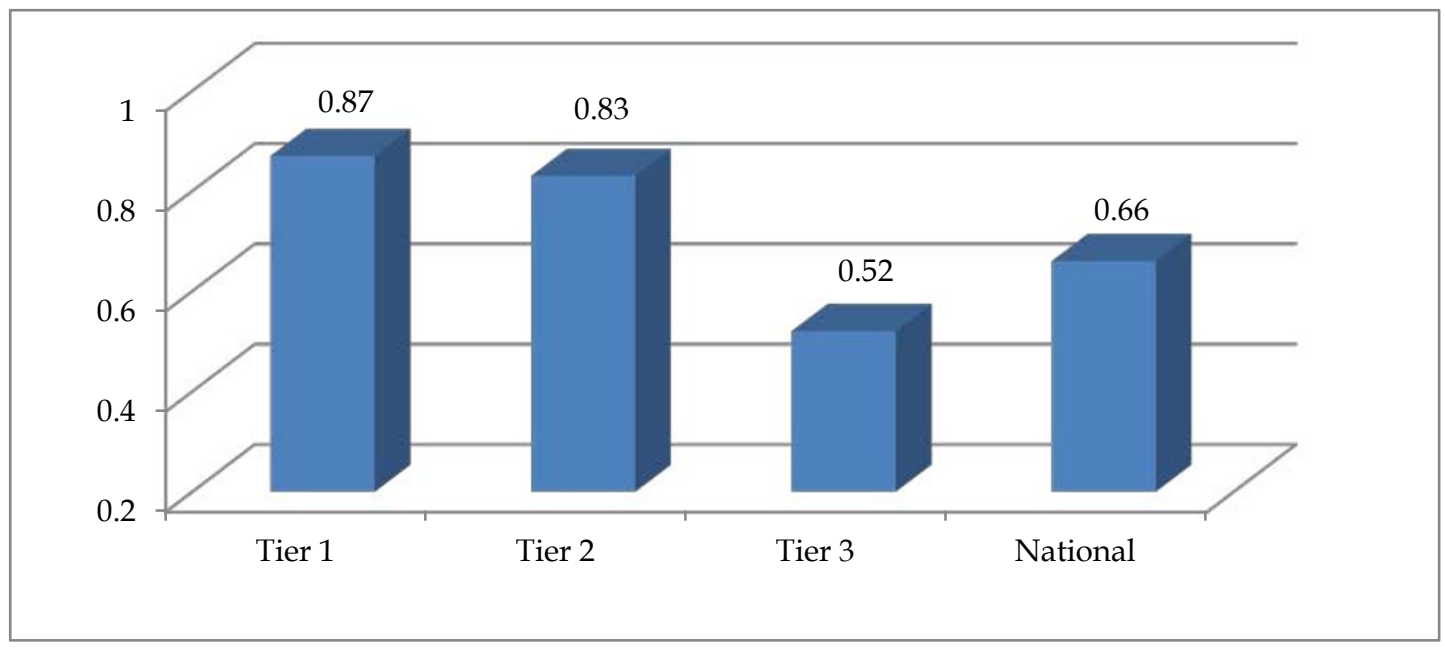

Figure 2. The gross preschool enrollment rate in three tiers 


\section{Gross Preschool Enrollment Rate}

The gross preschool enrollment rate of Tier 1 was 0.87 and that of Tier 2 was 0.83 (see Figure 2), both of which had reached high levels. However, the gross preschool enrollment rate of Tier 3 was only 0.52, which was far below the national average (0.66). Notably, the gross preschool enrollment rate in Zhejiang province was 1.14, higher than 100 percent, an anomaly which might have resulted from our calculation method. In our study, gross preschool enrollment rate $=($ total number of enrolled children - number of enrolled non-local resident children) $\div$ (number of 3- to 6-year-old local resident children number of migrant 3-to 6-year-old local resident children). However, it was difficult to obtain the number of enrolled non-local resident children and the number of migrant 3-to 6-yearold local resident children in each area. As a result, the gross preschool enrollment rate might be higher than the actual rate in the areas such as Zhejiang province, where they have a large proportion of transient population.
The gross preschool enrollment rate in 18 provinces among 31 throughout the country was rather low, at no more than 0.66. The gross preschool enrollment rate in Tibet province in Tier 3 was only 0.16 , which was the lowest nationwide and matched its development of elementary education (Xue \& Hu, 2004).

\section{Preschool Student-to-Teacher Ratio}

As shown in Figure 3, preschool student-to-teacher ratio increased positively from Tier 1 to Tier 3 . The student-to-teacher ratio of Tier 1 (Beijing and Shanghai) was 14, which was lower than others. This meant preschools in Beijing and Shanghai had a relative sufficiency of teachers. The student-to-teacher ratio of Tier 2 was 26 , better than the national average student-to-teacher ratio in Mainland China, though it could not reach the level of Tier 1. The student-to-teacher ratio of Tier 3 was 30.4, higher than the national average by 2.85 , more than double current ratio of Tier 1 . These data showed that the supply of

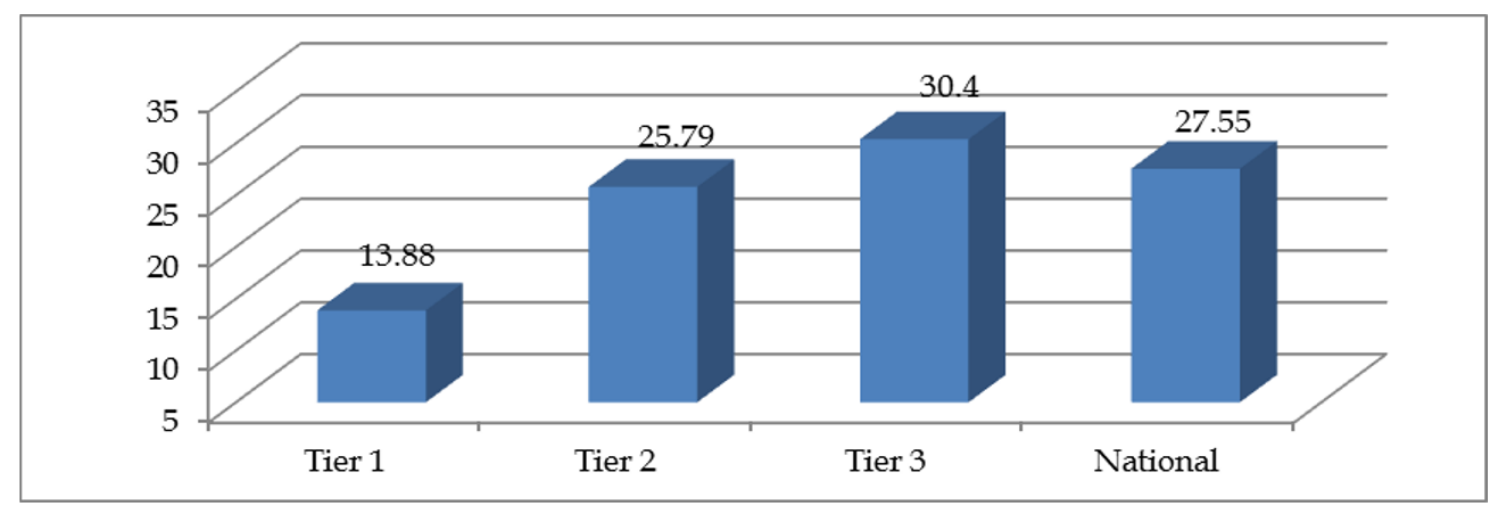

Figure 3. Preschool student-to-teacher ratio in three tiers 
preschool teachers in Tier 3 was obviously inadequate and could not meet the needs of children in these areas. In Tier 3, preschool student-toteacher ratio in Xinjiang province and Guizhou province was higher than 41; in fact, the ratio of Guizhou province almost reached 52, which stand as a severe "red flag" and urgently needs to be addressed. In addition, there were 16 provinces in 31, whose preschool student-to-teacher ratios were higher than the national average ratio. All of these areas were in the central and western regions, indicating that preschool teacher resource in the central and western regions was far behind the eastern region.

\section{Percentage of Preschool Teachers with a College Diploma or Above}

As for preschool teachers' educational level, the proportion of preschool teachers who obtained college education or above in Tier 1 was 93 percent (see Figure 4), indicating that the quality of preschool teachers in Beijing and Shanghai was the highest in Mainland
China. The percentage of preschool teachers with a college diploma or above in Tier 2 was 66 percent, far from the national average. This lower percentage was due to fewer than 60 percent of preschool teachers in Jiangxi, Guangdong, Fujian and Hainan provinces having a college diploma or above. It was surprising that our study showed that the percentage of preschool teachers with a college diploma or above in Tier 3 was nearly 80 percent, which was much higher than that in Tier 2. This finding might show that most preschools in Tier 3 had been equipped with qualified and high quality teachers. With the Chinese central government's "Go West" campaign in 12 western provinces in 1999 and its relevant policies, the exploration of education and human resources was a vital area of focus. Through the implementation of The Special Project for Personnel Training in the Western Region, excellent college graduate volunteers were attracted to work in the remote western areas, and an urban and rural teachers exchange system was established.

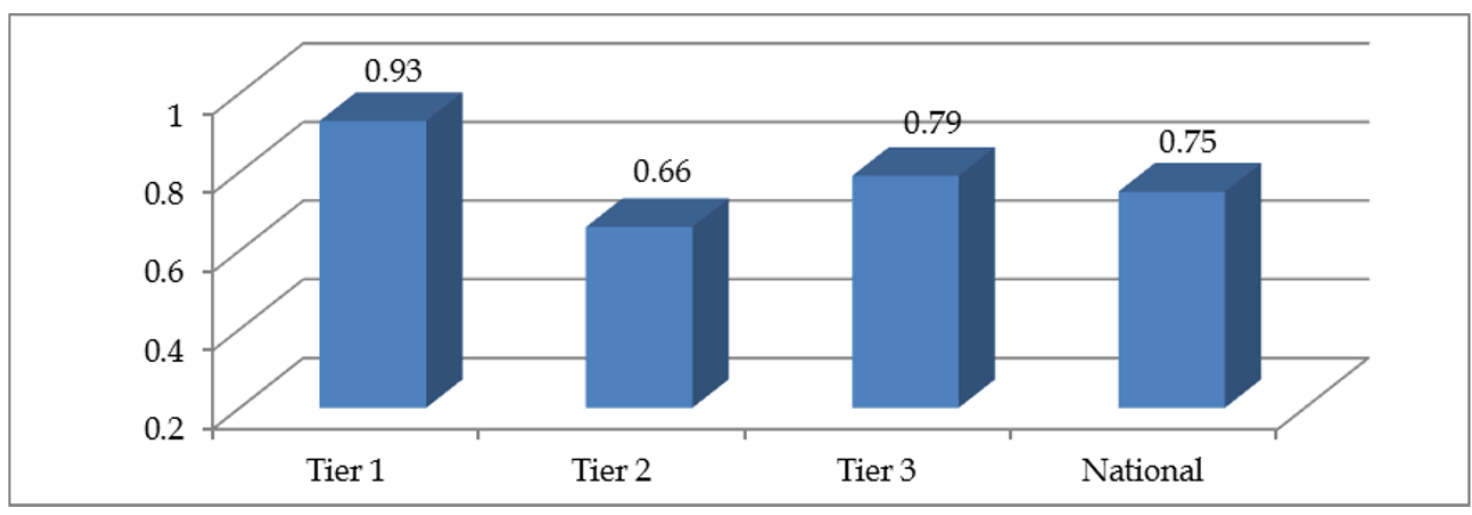

Figure 4. Percentage of preschool teachers with a college diploma or above in three tiers 
These policy measures might contribute to the higher percentage of preschool teachers with a college diploma or above in the western region.

\section{Per-child Preschool Education Spending Index}

The per-child preschool education spending index is a critical indicator measuring the importance attached to preschool education by the government and society as well as the investment in different regions. In most situations, the amount of per-child preschool education spending index depends on the GDP per capita in that region. Although the difference in this indicator across three tiers was only at .05 alpha level, there were huge gaps between different tiers on preschool expenditure per child -the absolute investment of preschool education spending per child. As shown in Figure 5, the preschool expenditure was 15,622 Yuan per child in Tier 1 , which was 4.2 times of that in Tier 2, and 5.3 times of that in Tier 3. The preschool expenditure was 3,720
Yuan per child in Tier 2, which was lower than the national average. However, the preschool expenditure per child in Tier 3 was very low, only 2,942 Yuan, which was only equal to 65 percent of the national average. One reason for regional disparity on preschool expenditure is the current educational expenditure system in Mainland China -a very small proportion of educational expenditure from the central government, with local government taking lead responsibility for educational expenditure.

We conducted multiple univariate tests (ANOVA) of the tiers on each of the four internal variables of preschool education. The results revealed that there were statistically significant differences among three tiers at .05 alpha level across gross preschool enrollment rate, student-to-teacher ratio, percentage of preschool teachers with a college diploma or above, and per-child preschool education spending index. Post hoc analysis (Scheffe's method) was performed for further identification of the differences on three variables. As

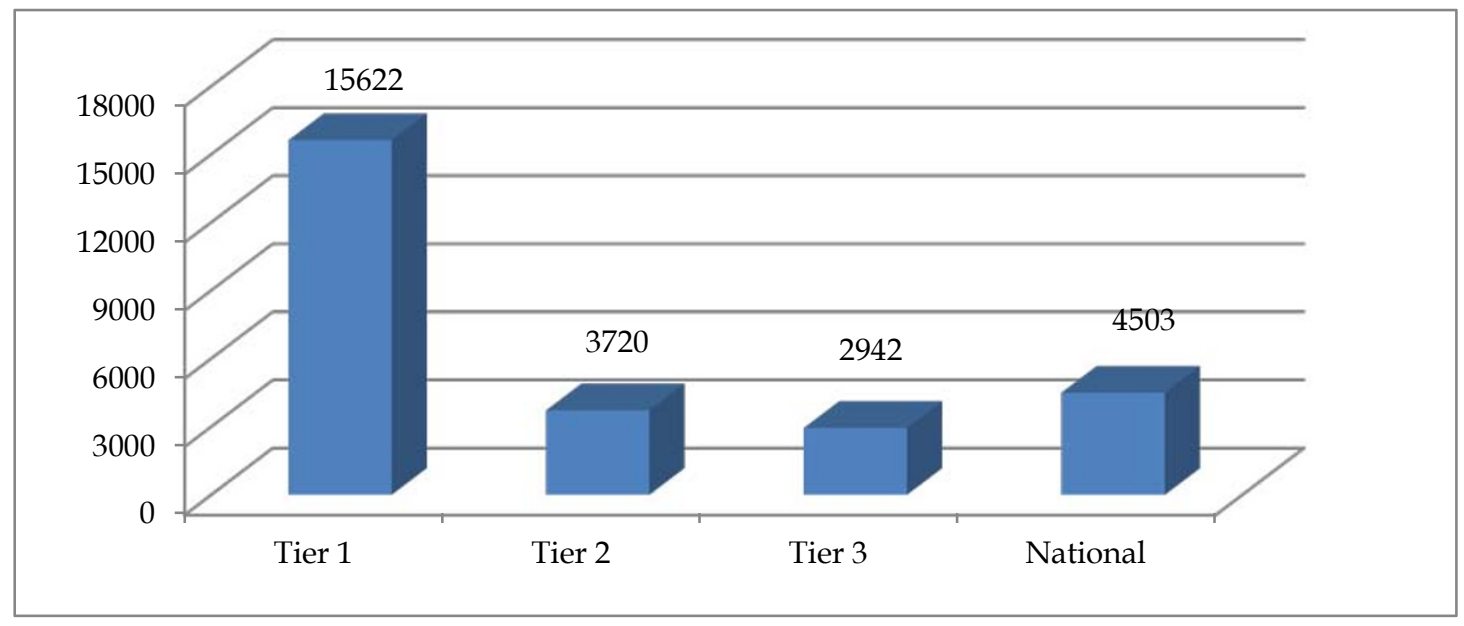

Figure 5. Appropriations (Yuan) for preschool education per child in three tiers 
Table 2. Means, Standard Deviations, and Analysis of Variance Results of Tiers (N=31)

\begin{tabular}{|c|c|c|c|c|c|c|c|c|}
\hline \multirow{2}{*}{ Variables } & \multicolumn{2}{|c|}{ Tier 1} & \multicolumn{2}{|c|}{ Tier 2} & \multicolumn{2}{|c|}{ Tier 3} & \multirow{2}{*}{$\frac{\text { ANOVA }}{\mathrm{F}}$} & \multirow[t]{2}{*}{ Scheffe's } \\
\hline & M & $S D$ & M & $S D$ & M & $S D$ & & \\
\hline $\begin{array}{l}\text { Gross preschool } \\
\text { enrollment rate }\end{array}$ & 0.87 & 0.02 & 0.83 & 0.17 & 0.52 & 0.12 & $20.51^{* * *}$ & Tier 1,2 > Tier 3 \\
\hline Student-to-teacher ratio & 13.88 & 1.56 & 25.79 & 6.15 & 30.40 & 823 & $5.12^{* *}$ & Tier $1<$ Tier 2,3 \\
\hline $\begin{array}{l}\text { Percentage of preschool } \\
\text { teachers with a college } \\
\text { diploma or above }\end{array}$ & 0.93 & 0.11 & 0.66 & 0.11 & 0.79 & 0.07 & $12.31^{* * *}$ & Tie $1>$ Tier $3>$ Tier 2 \\
\hline $\begin{array}{l}\text { Per-child preschool } \\
\text { education spending index }\end{array}$ & 19.08 & 0.41 & 8.13 & 287 & 13.34 & 8.86 & $3.19^{*}$ & Tier $1,3>$ Tier 2 \\
\hline
\end{tabular}

Note: ${ }^{*} \mathrm{p}<.05,{ }^{* *} \mathrm{p}<.01,{ }^{* * *} \mathrm{p}<.001$. Scheffe's post hoc analysis denoting pairs of tiers that are significantly different at .05 alpha level.

shown in Table 2, the mean values in Tier 2 across each variable were statistically significantly lower than those in Tier 1 except for the gross preschool education rate. Areas in Tier 3 had the lowest gross preschool education rate, just over 50 percent, but eighty percent of preschool teachers in those areas had received college education or above, which was higher than that of Tier 2. In our study, the capital Beijing, and Shanghai, the economic center of China, which are the most important and developed provinces, fell into Tier 1 , showing their preschool education at the highest level of development in Mainland China. Results of post hoc analysis further showed that Beijing and Shanghai were statistically significantly higher than other areas across most variables.

In this study, we found that areas in Tier 3 had statistically significant higher per-child preschool education spending index than areas in Tier 2, which was inconsistent with the overall result that preschool education development in Tier 2 was superior to Tier 3. This finding might have resulted from the recent policies and trends in preschool education in Mainland China. In the Outline of China's National Plan for Medium and Long-term Education Reform and Development (2010-2020), a series of major projects were planned to promote equal access to education and raise education quality including the Promoting Preschool Education in Rural Areas Project. This project highlighted the fact that impoverished areas in the central and western regions shall gain the special funds and supports. According to the Treasury Department, in 2011 the central government set up special funds for the development of preschool education, and invested a total of 3 billion Yuan in supporting preschool education development both in the central and western regions and in ethnic minority areas. 


\section{Discussion}

Overall, the development of preschool education in Mainland China is severely unbalanced among regions, which affects and constrains the process of universalizing preschool education. Data from our study showed that the gross preschool enrollment rate of 13 provinces of 31 provinces was less than 60 percent in the year of 2011, especially so where preschool education was only available for less than a half of eligible young children in Tibet, Gansu, Qinghai, and Guizhou provinces. A majority of these 13 provinces are located in the under-developed western region or agricultural provinces in the central region. Thus, the economic and urbanization level is a key factor related to the preschool gross enrollment rate. The regional disparities of preschool education are deeply rooted in the extremely unbalanced pace of economic development in different regions. Low economic and urbanization levels have hindered the preschool gross enrollment rate in Mainland China. What's more, preschool education in Mainland China has suffered fiscal impoverishment for a long period of time. From 1993 to present, the education investment toward preschool education accounted for merely 1.3 percent of the total (Liu, 2009). Preschool education is more likely to be viewed as a private endeavor and is therefore greatly influenced by family economic status in the poor and backward areas of Mainland China, a situation which enlarges the educational gaps across different regions (Du, 2000). Only young children whose families have the capacity to afford the high fees can access preschool education in Mainland China. In order to narrow regional disparity, preferential policies should be developed earmarking more funds and resources in favor of the impoverished central and western regions. Based on the economic level and population distribution in the central and western regions, preschoolers would benefit from the diversified preschool management mechanism that includes social participation and pools both public and private resources. These areas should draw support from Chinese National Program of Central Preschools Construction in Villages and Towns, such as building independent preschools in big towns and villages while setting up branches or joint ones in small villages, even forming mobile preschools or seasonal classes in remote rural areas, to push forward and accelerate the availability of preschool education in the poor and backward areas so that every child enjoys equal access to a sound education.

At present, preschool teachers in Mainland China do not have equal salaries and social status compared with elementary teachers. In rural and underdeveloped areas, preschool teachers have to grapple with dreadful realities such as un-admitted identity, arduous working environment, heavy workload, limited training opportunities, dismal career prospects, and lack of qualifications for professional rank assessment and promotion (Chen, 2007). Given this dreadful environment, it is not surprising that preschools in developed and eastern 
regions are more attractive to teachers. For example, Beijing put 5 thousand million Yuan into building 118 new kindergartens in 2010. This large amount of investment may improve the salary of teachers. By contrast, it is difficult to provide such opportunity and conditions in the central and western regions due to policy restrictions and money, which might lead to preschool teacher turnover and teacher shortages. Thus, the supply of preschool teachers should be expanded through various channels. One the one hand, the enrollment of preschool teachers in the impoverished areas should be increased through free training and special subsidy programs, and by subsidizing volunteer preschool teachers. On the other hand, taking the opportunity of primary and middle school layout adjustment, primary teachers graduated from the early childhood education programs should be transferred back to preschools and some primary school teachers could work with preschoolers after training, which can effectively make up the serious shortage of preschool teachers in the impoverished central and western regions in a short period of time.

According to Teachers Law of the People's Republic of China, the entry requirement for being a preschool teacher is a diploma from a "normal" school with concentration on early childhood education which certifies not only high-school level of education but also three years of professional preservice training (National People's Congress, 1994, Article 11).A high quality teaching force promotes young children's optimal development and learning. A teacher who has a bachelor's degree with specialized education related to early childhood was recommended to be assigned in each preschool classroom (Bowman, Donovan, \& Burns, 2000). However, preschool teachers even in the eastern coastal regions such as Shandong, Guangdong and Fujian provinces had lower educational levels; fewer than 60 percent of the preschool teachers had attained college educations or above. Teachers' low educational level has become the bottle-neck for preschool education development in Mainland China. To solve this issue, enhancing the preschool employee admittance threshold is of great importance. First, the qualification and assessment of preschool teachers should be strictly regulated. Second, more normal universities or colleges should open early childhood education programs, which could improve the educational level and quality of preschool teachers. Moreover, training of rural preschool teachers that constantly enhances their capability and quality should be reinforced by increasing financial support to nurture more first-rank preschool teachers in the central and western rural regions. Setting up national and provincial special funds for teacher training in the impoverished rural areas would assist in this effort. 


\section{Conclusions}

In this paper, the authors discuss the unbalanced development of preschool education in 31 provinces in Mainland China. On the basis of the educational data of 2011, preschool education developmental status of 31 provinces in Mainland China could be divided into three levels. Regional disparities were embodied in the gross preschool enrollment rate, student-to-teacher ratio, percentage of preschool teachers with a college diploma or above, and per-child preschool education spending index. Data suggest that promoting the development of preschool education in the central and western regions should be the priority.

Future research on the unbalanced regional development of preschool education in Mainland China should take several dimensions into account. Progress in preschool educational development will be hindered if any one of these dimensions is ignored. It is significantly important not only to improve the quantity of preschool education, but also to improve its quality. Only in this way can we ensure steadily increasing progress and balanced development as well as coordinated development of preschool education in Mainland China, and in the process drawing closer to the goal of universalizing preschool education as stipulated in the country's national education plan for the next decade.

\section{References}

Bowman, B. T., Donovan, M. S., \& Burns, M. S. (Eds.). (2000). Eager to learn: Educating our preschoolers. Washington, DC: National Academy Press.

Cai, Y. Q., \& Feng, X. X. (2004). On the orientation of fair value and its realization in our policy for preschool education. Jiaoyu yu jingji (Education and Economic), 2, 33-36.

Chen, Q. (2007). Chinese rural preschool teacher's living environment and related suggestions. Dang daijiaoyuluntan [Forum on Contemporary Education], 4, 22-23.

China Education and Human Resource Problems Research Team. (2003). Stride from a country of tremendous population to a country of profound human resource. Beijing: Higher education Press.

Communist Party of China Central Committee \& State Council. (2010). Guajia zhong changqi jiaoyu gaige he fazhan guihua gangyao, 2010-2020 Nian [Outline of China's national plan for medium and long-term education reform and development, 2010-2020], Zhongguo jiaoyu bao [China Education Daily], July 30, pp1-3.

$\mathrm{Du}, \mathrm{W}$. (2005). Does Economic Growth Bring about the Enhancing of People's Life Quality? Shanghai Economic Review, No. 6.

Du, Y. H. (2000). Research on unbalanced education development. Beijing: Beijing Normal University Press.

Fan, C. C., \& Sun, M. (2008). Regional inequality in China: 1978-2006. Eurasian 
Geography and Economics, 49(1), 1-20. doi: 10.2747/1539-7216.49.1.1.

Jia, S. L., \& Liu, J.Y. (2011). Analysis of financial investment and policy options on regional preschool education balanced development: Shaanxi province as an example. Shaanxi jiaoyu xueyuan xuebao [Journal of Shaanxi Institute of Education], 4, 9-13.

National People's Congress. (1994). Teachers Law of the People's Republic of China. Retrieved from http://www. moe.edu. cn/publicfiles/business/htmlfiles/moe/ moe_619/200407/1314.html

Organization for Economic Co-operation and Development. (2005). Education at a Glance 2005: OECD Indicators, OECD Publishing. doi: 10.1787/eag-2005-en.

Peng, L. Q. (2007). The characteristics of industrial structure and its trends of regional transfer in the eastern, central and western regions. Jingji zong heng [Economic Review], 6, 29-31.

Tan, P. N., Steinbach, M., \& Kumar, V. (2006). Introduction to data mining. MA: Addison Wesley.

Wang, J., \& Shu, D. (2012). Research on the differences of economic fluctuation of China's eastern, central and western regions. Jingii yu guanli yanjiu [Research on Economics and Management], 9, 5-11.
Wang, S. M., Du Y. H., \& Liu, Y. X. (1998). The empirical analysis on unbalanced development of education in China. Jiaoyu Yanjiu [Educational Research], 6, 19-23.

Wei, J., \& Song, Y. (2011). Research on the balanced regional development of preschool education in China: From the perspective of education equity. Jiaoyu daokan [Journal of Educational Development], 9, 12-16.

World Bank. (2011). Early childhood development and education in China: Breaking the cycle of poverty and improving future competitiveness (Rep. No. 53746-CN). Washington, DC: The International Bank for Reconstruction and Development/the World Bank.

Xu, J. C., \& Ma, S. C. (1997). Research on unbalanced regional development of nine years compulsory education in China. Shanghai jiaoyu keyan [Shanghai Research on Education], 2, 26-29.

Xue, H. P., \& Hu, Y. M. (2004). Research on unbalanced regional development of basic education in China. Jiaoyu lilun yu shijian [Educational Theory and Practice], 2, 8-10. 